\title{
THE APRIL 2007 SWARM IN TRICHONIS LAKE USING DATA FROM A MICROSEISMIC NETWORK
}

\author{
Sokos E. ${ }^{1}$, Pikoulis V.E ${ }^{2}$, Psarakis E.Z. ${ }^{2}$ and Lois A. ${ }^{1}$ \\ ${ }^{1}$ University of Patras, Department of Geology, Seismological Laboratory, 26500 Patras, Greece, \\ esokos@upatras.gr,lois@upatras.gr \\ ${ }^{2}$ Department of Computer Engineering and Informatics, University of Patras, 26500 Patras - Greece, \\ pikoulis@ceid.upatras.gr,psarakis@ceid.upatras.gr,
}

\begin{abstract}
A series of strong earthquakes took place at the Trichonis lake area, during April 2007. Three events, with M 5.0 occurred within one day, causing damages to almost all nearby villages and especially at the small town of Thermo. The sequence lasted for more than one month with small to moderate size events. It was recorded by regional networks and results related to its time and space evolution have already been published. Just after the major events a microseismic network was deployed in the area, by the University of Patras, Seismology Laboratory. Eight stations were installed, with short period, three component sensors and portable digital recorders. The network was in operation for a period of one month and a lot of events were recorded by enough stations to provide a reliable location. We present here the analysis of these data using modern methodologies like waveform cross-correlation techniques and further relocation of the events using waveform based differential time. The results partially support the findings of the regional networks, as regards the gross characteristics of the aftershock sequence, but provide an enhanced description of it. The space time evolution of the aftershock sequence reveals the activation of more than one fault in the area and suggests the connection of the sequence with an unmapped fault.
\end{abstract}

Key words: Trichonis Lake, seismotectonics, relocation, double-difference, clustering algorithms, graph partitioning, cross-correlation.

\section{Introduction}

On April 2007 an earthquake sequence occurred at the eastern side of Trichonis Lake, in western Greece. The sequence initiated with small events on the $8^{\text {th }}$ of April 2007 and two days later the three strongest events of the whole sequence occurred (April 10th at 03:17,07:15 and 10:41 GMT) with magnitudes ranging from Mw 5.0 to Mw 5.2. The seismic activity continued for more than a month with smaller events. Research studies for this sequence have been published by Evangelidis, 2008 and Kiratzi, 2008. Both papers use regional data to study the characteristics of the seismic sequence, to correlate it with another series of earthquakes that occurred in the 70's in the same area and to identify the causative fault. This was identified by both studies to be a NNW-SSE normal fault, which bounds the south west bank of the Lake (Fig.1).

On the $11^{\text {th }}$ of April 2007 - one day after the strongest events - a portable microearthquake network was deployed in the area, by the University of Patras, Seismological Laboratory. Eight digital sta- 

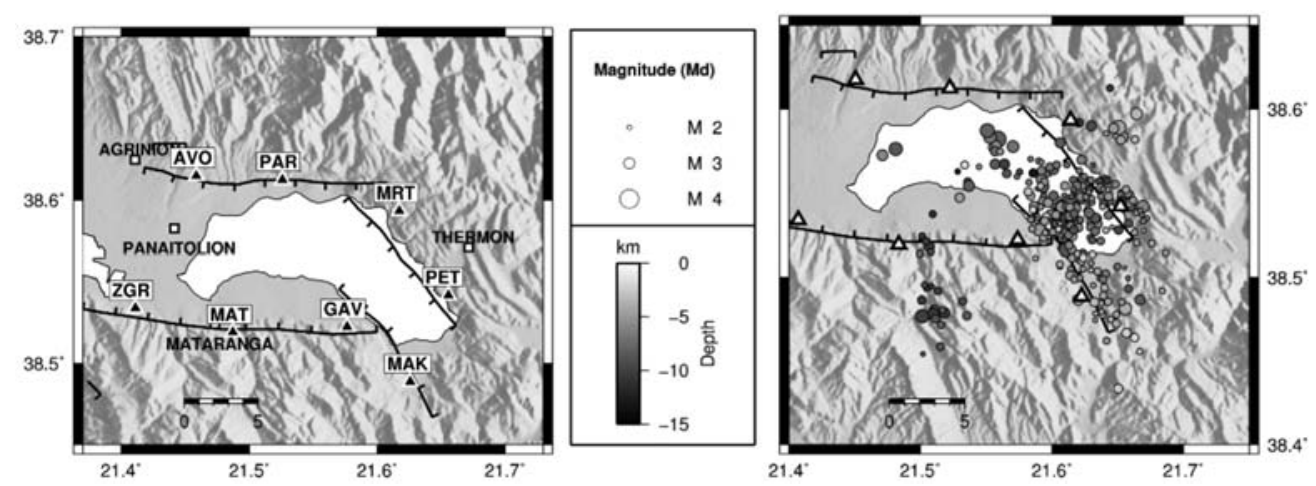

Fig. 1: (left): Simplified map showing the main faults of Trichonis graben and network configuration (right): Map of epicentres calculated using HYPOINVERSE.

tions (Fig.1), with short period sensors $(0.5$ to $50 \mathrm{~Hz})$, digital recording and GPS timing were installed. The network was kept in operation for twenty days and recorded accurately the evolution of the aftershock sequence. In this paper we present the results of the processing of these data using modern relocation techniques.

\section{Geological - Tectonic Setting}

The broader area of Trichonis lake is an active graben (Doutsos ,1987) with WNW-ESE strike and a length of about $30 \mathrm{~km}$ (Fig.1). It is formed almost perpendicular to the Hellenides fold and thrust structures and is bounded by large normal faults. The main geological formations in the area are flysch and limestone; parts of Pindos and Gavrovo isopic zones. The Trichonis graben is developing in a direction almost parallel to other active structures in the area, e.g. the Corinth, Patraikos and Amvarakikos gulfs, while it lies in between them. These structures are controlled by the north-south extension, present in the area and indicated by seismicity, focal mechanisms and GPS measurements (Papazachos and Kiratzi, 1996; Cocard, 1999).

The main tectonic feature in the area is the Trichonis lake fault that bounds the graben to the south and forms a distinct topographic escarpment (Doutsos , 1987). Nevertheless this fault didn't rapture during the earthquake sequence under study, as suggested by Evangelidis, 2008 and Kiratzi et al., 2008. The causative fault of this sequence strikes NNW-SSE and controls the topography of the lake at its eastern part, probably acting as a transfer fault that links the Trichonics lake with Corinth gulf (Melis et al., 1989). Similar faults are proposed for linking Trichonis graben to Corinth Gulf and Amvrakikos Gulf e.g. Katouna fault zone (Melis et al., 1989; Doutsos and Kokkalas, 2001).

\section{Data}

A portable network of 8 stations was installed in the area for twenty days ( $11^{\text {th }}$ April $2007-1^{\text {st }}$ June 2007) (Fig. 1). The station spacing was chosen to be less than $10 \mathrm{~km}$ to have reliable focal-depth estimation and in the meantime have a good azimuthal coverage of the aftershock sequence and record possible events on the main Trichonis lake fault that strikes EW. Each station was equipped with a three-component 4-Hz SIG borehole sensor, a 24-bit Earth Data recorder, and a Global Positioning System (GPS) unit. The instruments have flat transfer function for velocity in the frequency range from $0.5 \mathrm{~Hz}$ to $50 \mathrm{~Hz}$. Recording was continuous with a sampling frequency of $100 \mathrm{~Hz}$. A special pro- 
gram was developed, based on the STA/LTA (short-term average/long-term average) algorithm, to identify seismic events and store files for later processing. A minimum number of four stations was used as criterion for event selection. During the operation of the network more than 700 earthquakes were identified and seismic phases were handpicked. The initial hypocentral locations were determined using the HYPOINVERSE program (Klein, 2002). The velocity model adopted was the one proposed by Haslinger et al., 1999, which was derived by tomography studies in the broader area. From this initial catalogue, we selected 335 events having more than 12 arrivals (P and S) and epicentres within the network. The magnitudes were computed using the coda duration method (Lee et al., 1972), and computed duration magnitudes (Md) range within 1.11 and 3.2, whereas their depths vary between 1 and $15 \mathrm{~km}$. (Fig.1). Although this is a high quality dataset, with small formal hypocentral errors $(\sim 1 \mathrm{~km})$, it is not suitable for correlation with mapped faults in the area, thus a relocation technique was designed and applied to the data, during further processing.

Nevertheless, a few important features of the aftershock sequence are evident even by applying only standard location methods. These are similar to results obtained by Evangelidis et al. (2008) and Kiratzi et al. (2008). Thus, as seen in Fig.1, the seismicity is constrained mainly in the eastern part of the lake bounded by two NW-SE normal faults while there are only a few events to the west that could be correlated to the main EW trending Trichonis lake fault. What is new and not described in previous studies, is a cluster of events south of Trichonis lake fault, with a NNW-SSE trend, located in a depth of $\sim 10 \mathrm{~km}$. This cluster appeared twelve days after the main events and is formed by small magnitude events (largest magnitude was $2.7 \mathrm{Md}$ ). It is probably related to reactivation of an older structure, due to stress transfer by the main events but this needs support by a separate study, which is beyond the scope of this paper.

\section{Identification of Event Clusters and Time Differences}

One of the most critical tasks involved in the relocation problem is the identification of the event clusters from a given set of events. This task is carried out in two stages.

The first one involves the comparison of all the possible pairs of seismograms of the data set in order to determine their pairwise similarities. For the comparison of individual seismograms, we use a correlation based technique (Pikoulis et al., 2006) that outperforms the classic method that is based on the maximization of the correlation coefficient. The motivation behind the development of this method was the observation that different parts of the waveforms have different impact on the value of correlation coefficient (Pikoulis et al., 2006). In particular, the contribution of each part was found to be strongly depended on its energy. Therefore, the similarity (or the dissimilarity) of the high energy waves, such as $\mathrm{S}$ and surface waves, will have a much greater impact on the value of correlation coefficient than the similarity of the low energy waves, such as the $\mathrm{P}$ wave, which is undesirable. The proposed method is applied on continuous parts of seismograms containing both $\mathrm{P}$ and $\mathrm{S}$ onsets, and it is carried out in three steps. Specifically, in the first one the optimal linear alignment of the waveforms under comparison is obtained by finding the lag that maximizes their correlation coefficient. Next, by using a sliding time window over the linearly aligned waveforms, the initial signals are broken into a sequence of equally - sized overlapping blocks. Calculating the correlation coefficient of every corresponding block pair, as well as, of a large number of bootstrapped block pairs, results in a sequence of partial correlation coefficient values. Based on the statistical properties of these values, the similarity of the waveforms at hand is to be decided. This is performed in the third and final step of the procedure. Specifically, if we consider that each sequence is a sample of values drawn from a population with a specific probability density function (pdf), and if we also assume that the histogram 
of the values of the sequence is an approximation of this pdf, then our decision problem can be expressed as a typical hypothesis testing one. The outcome of the comparison stage is an undirected unweighted similarity graph, where each vertex represents a particular event of the data set, and there exists an edge between two vertices of the graph if and only if the corresponding events are characterized as similar by the above mentioned correlation based technique.

In the second stage, a clustering algorithm is needed in order to group the pairs of similar events into event clusters. In order to avoid the limitations of well known clustering algorithms such as the hierarchical methods, the $k$ - means, the fuzzy means, and the Expectation Maximization algorithm (Everitt et al., 2001, Bardaine et al., 2006, Becker et al., 2006), we propose a fast, sequential, graph based algorithm that exploits the structure of the similarity graph and produces a single cluster in each iteration. The proposed algorithm (Pikoulis et al., 2006) emphasizes on the quality of the produced clusters by introducing a suitable measure to evaluate the participation of each object to a cluster and by expressing the overall quality of the cluster as a function of the participations of the individuals that comprise it. Each iteration is a two - step procedure. In the first step by eliminating repeatedly the vertex with the lowest degree and all the edges incident to it, an ordering of the vertices of the graph is obtained. Note that this is not the same as sorting the vertices of the graph based on their initial degrees. The elimination of a vertex (and of the edges incident to it) will only reduce the degrees of the vertices that were adjacent to it. Thus, if the vertex eliminated on a given round is part of a dense and well - separated group of vertices then, with high probability the majority of the reduced degrees will come from vertices of the same group, which, due to the assumptions had similar degrees with the eliminated vertex. As a result, the vertex that will be eliminated on the next round will most likely also belong to the same group, and this will carry on until the whole group is eliminated. Based on this, we expect the outcome of this step to be a rough grouping of the vertices, with the smallest groups located towards the beginning of the eliminated sequence and the largest ones located towards the end of it. As we go deeper in the elimination rounds, the vertices that are still remaining towards the end of the procedure should not only have had more connections in the initial graph, than the ones already eliminated, but they should also have a great number of connections among them, as it is the number of these connections that allows them to survive the elimination rounds. In this sense, the lastly eliminated vertices should not only belong to the same cluster, but they should also form the most compact (densely connected) part of it, or its core (and the seismic events they represent form the core of the corresponding group). Therefore, the algorithm decides that has reached the core of a cluster, whenever the remaining part of the graph is a clique (every pair of vertices is connected by an edge) and terminates the elimination procedure. Having the identified clique as a starting point, in the next step the algorithm involves a procedure of augmentation rounds with the purpose of gradually forming the rest of the cluster around its core. In each round, of all the vertices that have not yet been added, the vertex with the higher number of connections with the already added vertices is selected. We anticipate that the first vertices to be added will be the remaining vertices of the cluster that will frame the initial core, followed by the rest of the vertices of the graph. This is because of the starting point of the augmentation procedure and the selection criterion of the vertex which is added in each round. What remains is the determination of the particular augmentation round where the procedure of cluster formation should be stopped. In order to achieve this goal, we introduce the term of participation of a vertex to a graph and define it as the ratio of the number of the edges in the graph that are incident to that specific vertex, to the maximum possible number of such edges (which occurs if the vertex is connected to all the other vertices of the graph). We also define as a quality measure of the graph the minimum value of participation among all the vertices that belong to it. A high value of this measure ensures that every 
vertex in the graph is connected to a high number of the other vertices and therefore there is a very high probability that the vertices of the graph are part of the same cluster. On the other hand, if the graph contains even as much as one vertex with few connections to the other members (an outlier), then its participation value will be low and this value will be reflected on the value of the measure. After each augmentation the algorithm calculates the value of the quality measure of the resulting graph and terminates the augmentation procedure if the value of the measure drops below a pre-selected threshold. The vertices of the identified cluster are deleted from the initial graph and the algorithm reiterates with the remaining vertices.

Finally, the computation of the time differences between events of the same cluster, is based on the maximization of a similarity measure called Enhanced Normalized Cross Correlation (ENCC) (Psarakis and Evangelidis, 2005), which constitutes an extension of the sample level correlation coefficient. The above mentioned similarity measure is a continuous function of the time lag parameter, thus leading to sub - sample accuracy. Moreover, its maximization has a closed form solution, resulting to a very low computational cost.

\section{Relocation}

The Double Difference (DD) relocation method proposed by Waldhauser and Ellsworth (2000), and implemented in HYPODD software (Waldhauser, 2001) was used for relocating the whole dataset. The DD method is a relative earthquake location method (e.g. Fréchet, 1985; Got et al., 1994; Roumelioti et al., 2003). It is based on the fact that when the hypocentral separation between two earthquakes is small compared to the event station distance and the scale length of the velocity heterogeneity, then the ray paths between the source region and a common station are similar along almost the entire ray path. In this case, the difference in travel times for two events observed at the same station can be attributed to the spatial offset between the events with high accuracy. This is because the absolute errors are of common origin except in the small region where the ray paths differ at the sources (Waldhauser and Ellsworth, 2000). The use of waveform cross-correlation methods improves the accuracy of the relative arrival-time readings, thus leading to highly accurate locations. According to Waldhauser and Ellsworth, 2000 the use of waveform cross-correlation methods can lead to relative locations between earthquakes, with errors of only a few meters to a few tens of meters.

As discussed above we computed cross-correlation, P-and S-wave differential travel-times for the 335 events and the defined 74 clusters. In order to access the contribution of each piece of information to final result we followed the following approach.

First we relocated the whole sequence using HYPODD clustering option and catalog absolute traveltime measurements only (CT-data). This is the most common approach when doing relocation with HYPODD and can serve as a reference point. This scheme consists of a) forming of event pairs and links to neighbors, b) formation of clusters and c) double difference relocation. Following, Waldhauser and Ellsworth, 2000, we selected only strongly connected events and this reduced our dataset by a few events. The final dataset consisted of $16576 \mathrm{P}$ and $11326 \mathrm{~S}$-wave phase pairs that were relocated using the conjugate gradients method (LSQR, Paige and Saunders, 1982). A pair of critical points exists when applying the above method a) which is the proper choice of damping and b) weights of data, for both of them we followed the suggestions of Waldhauser (2001). The crustal model used was again the model of Haslinger et al. (1999). In Fig. 2 the results obtained by applying HYPODD standard relocation scheme are presented.

In the next step, we implemented steps a) and b) of the scheme described in the previous paragraph by 


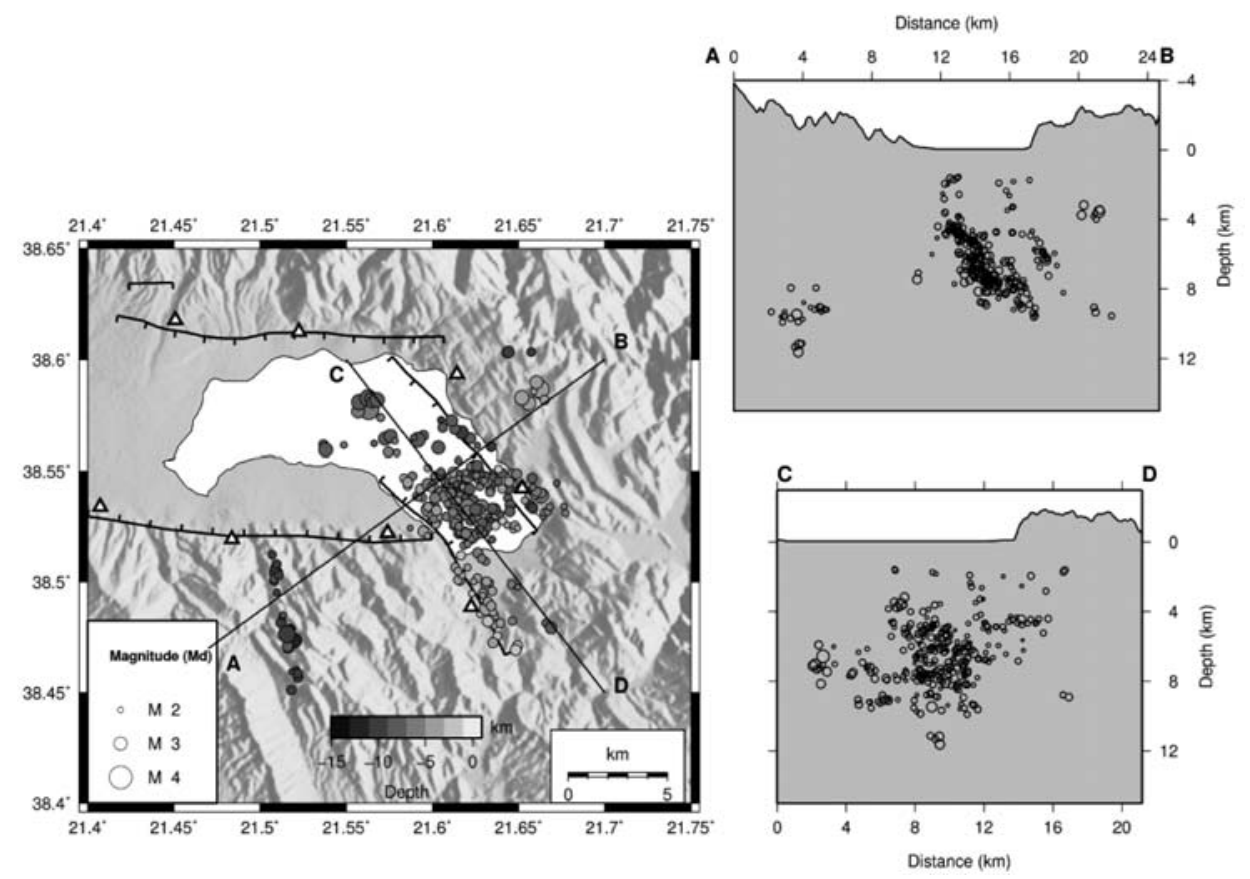

Fig. 2: Map view and cross sections of relocated epicenters applying the HYPODD relocation method. Topography is exaggerated by a factor 5 .

using the procedure described in Section 4 and relocated each of the identified clusters with HYPODD using CT data only. The results are presented in Fig.3, and are comparable to the simple HYPODD clustering and relocation. Finally we added to the inversion the differential travel times, computed by using ENCC described in the last paragraph of the previous section. This resulted in a quite different view of the sequence, the main cluster of hypocenters was divided to smaller clusters that follow the causative fault both in strike and dip (Fig.4).

\section{Discussion}

The relocated aftershocks of Trichonis lake 2007 sequence, using data from a local microseismic network, provided a detailed view of the time-space evolution of seismicity. The sequence initiated on the $8^{\text {th }}$ of April and on the $10^{\text {th }}$ three moderate size events occurred (Kiratzi et al., 2008). In Fig. 5 we present in map view the evolution of the sequence during the recording period $\left(11^{\text {th }}\right.$ of April $-1^{\text {st }}$ of May 2007), using the relocated data described in previous paragraphs. The main events of the sequence were not recorded by the microseismic network, thus we have included in the top left panel of Fig. 5 the location provided by Kiratzi et al. (2008) and Evangelidis et al. (2008) for the strongest one (star and square in top left panel of Fig. 5).

During the first two days, after the occurrence of the main events, the seismicity is confined in the south east part of the lake in an area of $5 \times 5 \mathrm{~km}$ approximately, in accordance with empirical scaling laws, (e.g. Wells and Coppersmith, 1994). There are two main clusters during this time period located at the southwest bank of the lake. The main event is located at the northwest end of the aftershock area, indicating a southward propagation of the seismicity. Furthermore the main event is located in an area free of aftershocks through the whole recording period. This is an indication of 


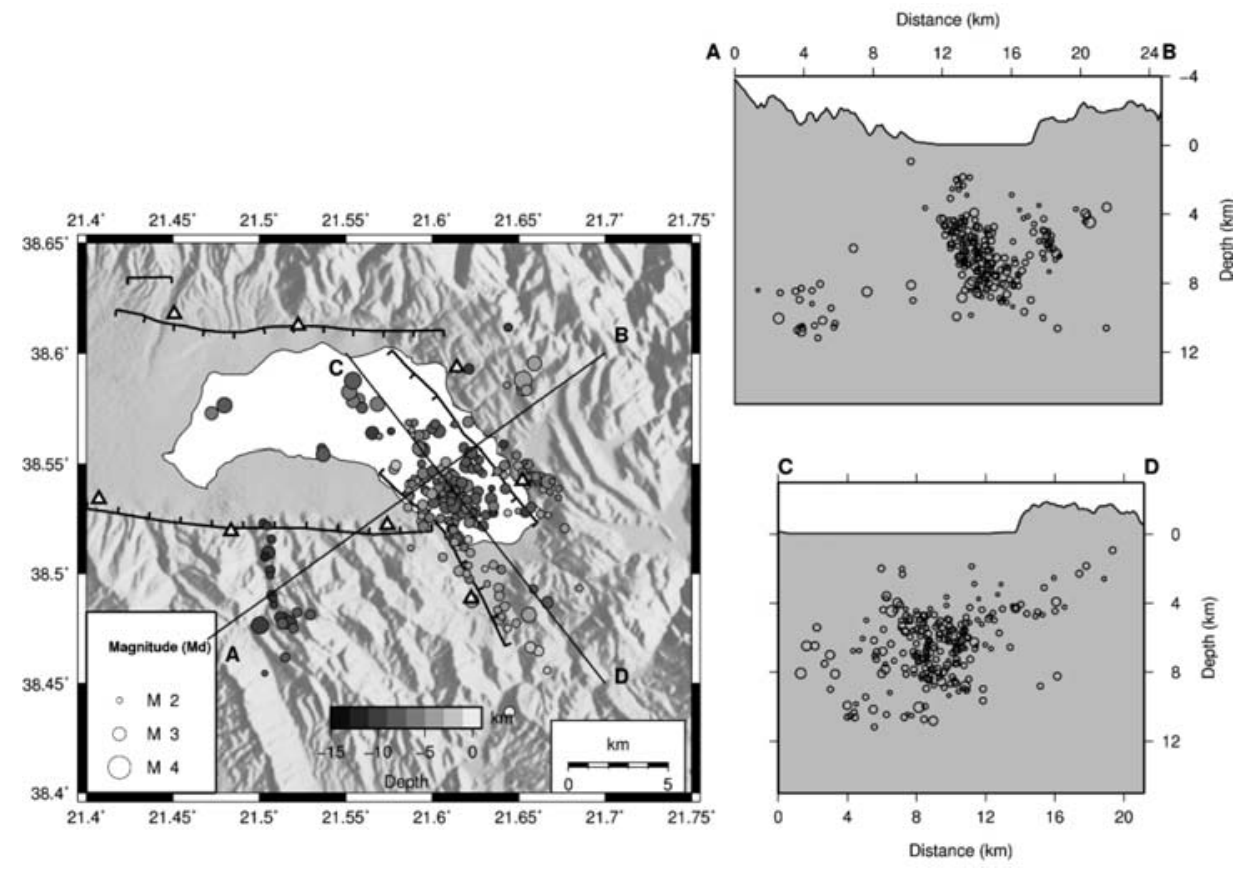

Fig. 3: Map view and cross sections of double difference relocated epicenters using our clustering scheme and CT data.

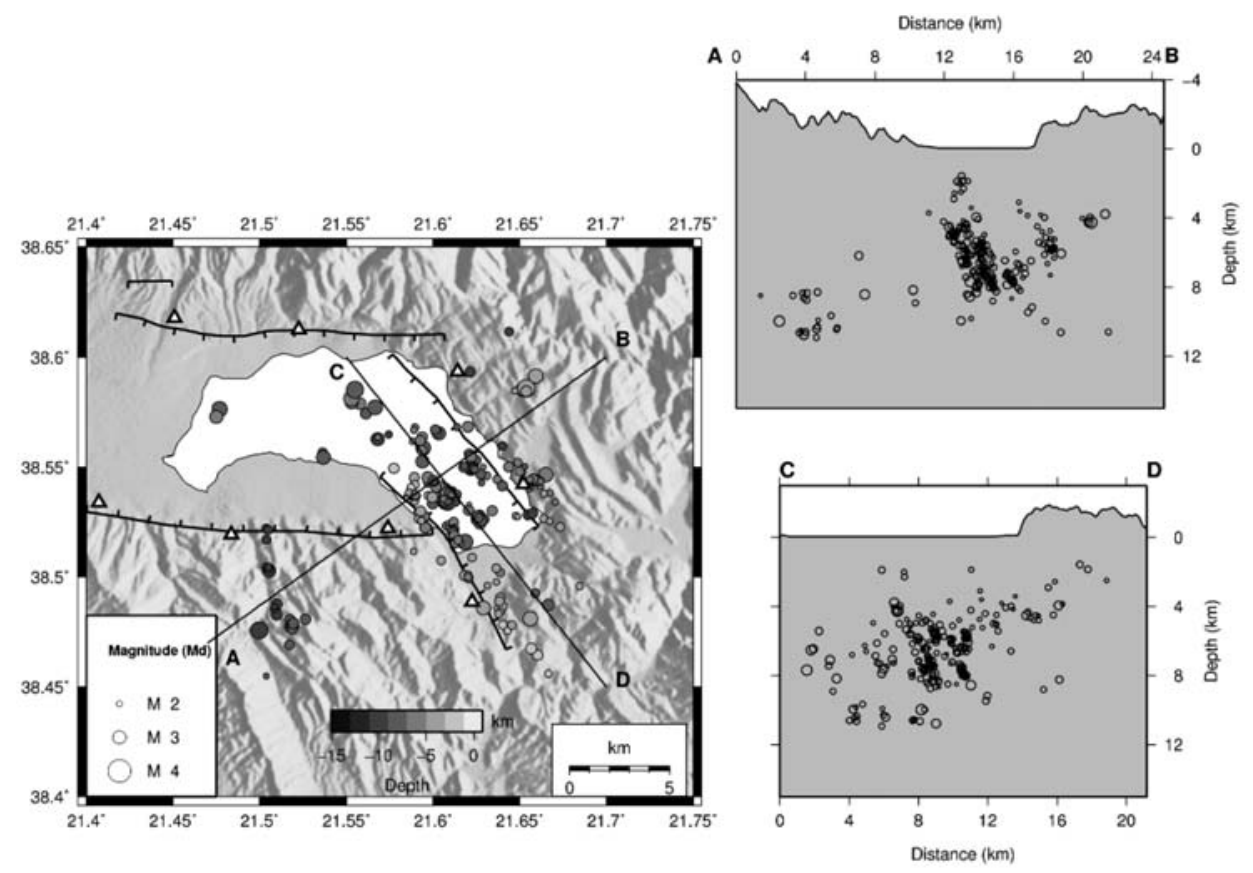

Fig. 4: Map view and cross sections of double difference relocated epicenters using our clustering scheme and both $\mathrm{CT}$ and $\mathrm{CC}$ data. 

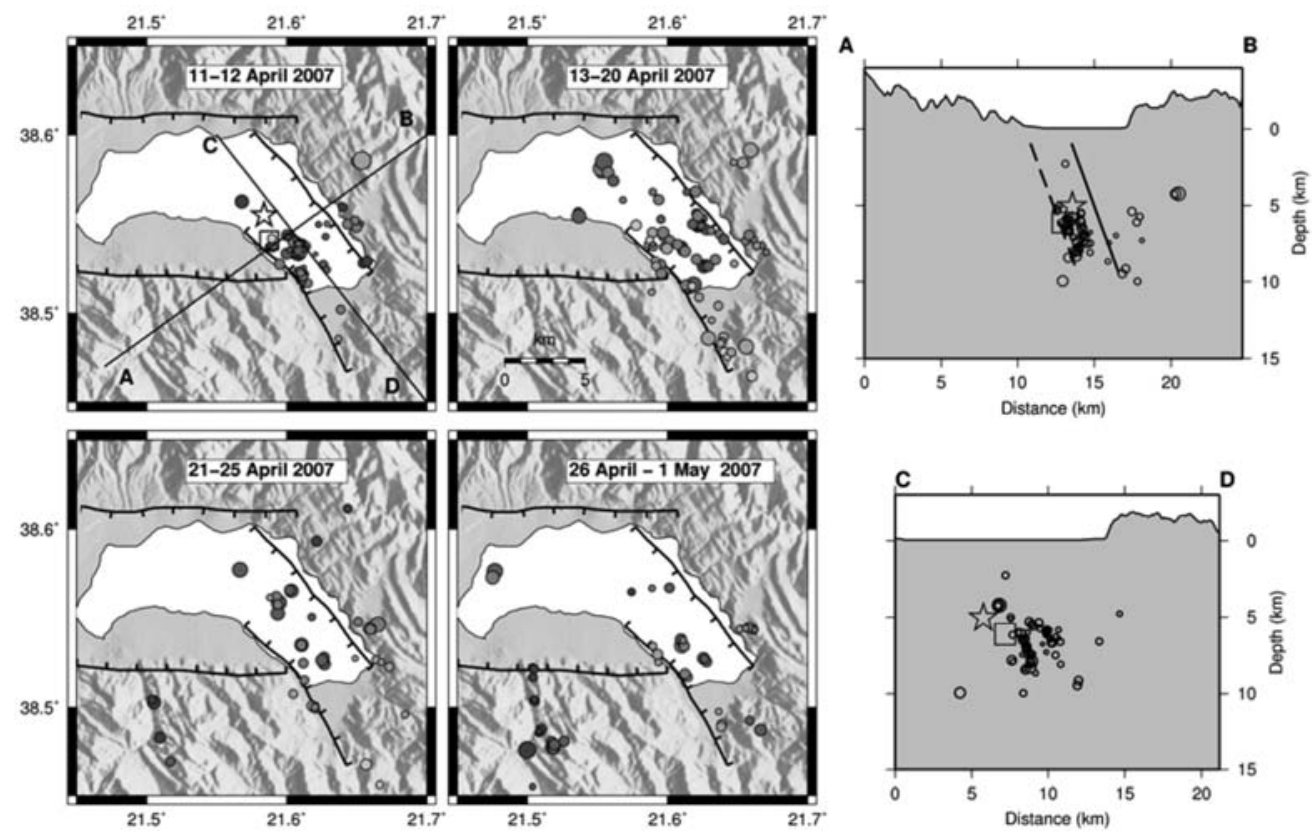

Fig. 5: Map view and cross sections of space-time evolution of aftershock sequence. Continuous line on $\mathrm{AB}$ cross section corresponds to mapped fault trace at the south bank of Trichonis lake, while dashed line corresponds to an inferred parallel fault, a dip of $70^{\circ}$ was used. Star and square denote the location of main event, see text for details.

complete stress release in this part of the fault during the occurrence of the strongest events of the sequence on the $10^{\text {th }}$ of April. The aftershocks depth distribution during the same time period $\left(11^{\text {th }}\right.$ $12^{\text {th }}$ of April) is depicted on the cross-sections of Fig.5. Seismicity forms a cluster at a depth of 5 to $8 \mathrm{~km}$ comparable to the depth of the main event (Kiratzi et al., 2008, Evangelidis et al., 2008). Hypocenters in this cluster form two linear shapes that have slightly different dip. Although it is difficult to connect these with fault traces on the surface, since the true geometry of the faults closer to the surface, is not known, we can speculate about activation of two faults in the area with slightly different dip and similar strike. According to Kiratzi et al. (2008) the focal mechanisms of the strongest events had a dip of $\sim 70^{\circ}$, using this dip and a linear fault geometry we can try to connect it with the depth distribution of aftershocks (Fig. 5). It is clear then that the NW-SE trending fault that bounds the south bank of Trichonis lake, cannot explain the whole aftershock distribution and we need a fault parallel to this $\sim 3 \mathrm{~km}$ to the west and on land. During the following days the aftershock activity started to spread in a larger area mainly towards the south and along the same NW$\mathrm{SE}$ direction. An interesting feature during the last ten days of recording ( $21^{\text {st }}$ April $-1^{\text {st }}$ May) is the development of a small cluster of events south of the Trichonis lake fault. This cluster has a similar trend (NW-SE) with the main aftershock sequence and events within it are distributed at 8 to $10 \mathrm{~km}$ depth. Since this cluster appeared a few days after the occurrence of the main events in the area, we can speculate about the possibility that is due to stress transfer. Of course a definite proof of this needs a special study which is beyond the scope of this paper. 


\section{Acknowledgments}

This work was partially financed by the University of Patras, "Karatheodori" research programs, with titles "Development of automatic seismic data processing techniques, for application to seismic tomography" and "The relocation problem of seismic event hypocenter parameters".

\section{References}

Bardaine T., Gaillot P., Dudos-Sallee N., Blanco J., Senechal G. 2006. Characterization of Seismic Waveforms and Classification of Seismic Events Using Chirplet Atomic Decomposition. Example from the Lacq Gas Field (Western Pyrenees, France). Geophys. J. Int., 166, pp 699-718.

Becker D., T. Meier, M. Rische, M. Bohnhoff, H.P. Harjes. 2006. Spatio - temporal microseismicity clustering in the Cretan region. Tectonophysics, 423, pp 3 - 16, 2006.

Cocard, M., Kahle, H.-G., Peter, Y., Geiger, A., Veis, G., Felekis, S., Paradissis, D., Billiris, H., 1999. New constraints on the rapid crustal motion of the Aegean region: recent results inferred from GPS measurements (1993-1998) across the West Hellenic Arc, Greece. Earth and Planetary Science Letters $172,39-47$.

Doutsos, T., Kontopoulos, N., Frydas, D., 1987. Neotectonic evolution of northwestern continental Greece. Geol. Rundsch. 76, 433-450.

Doutsos, T., Kokkalas, S., 2001. Stress and deformation patterns in the Aegean region. Journal of Structural Geology 23, 455-472.

Evangelidis C. P., Konstantinou K. I., Melis N. S., Charalambakis M., Stavrakakis G. N., 2008, Waveform relocation and focal mechanism analysis of an earthquake swarm in Trichonis lake, western Greece, Bull. Seism. Soc. Am. 98(2), pp. 804-811.

Everitt, B. S., Landau S., Leese M. Cluster Analysis ( fourth edition). Arnold, London, 2001.

Fréchet, J., 1985. Sismogenèse et doublets sismiques. Thèse d'État, Université Scientifique et Médicale de Grenoble, 206 pp.

Got, J.-L., Fréchet, J., Klein, F.W., 1994. Deep fault plane geometry inferred from multiplet relative location beneath the south flank of Kilauea. J. Geophys. Res. 99, 15375-15386.

Haslinger, F., Kissling, E., Ansorge, J., Hatzfeld, D., Papadimitriou, E., Karakostas, V., Makropoulos, K., Kahle, H.G., Peter, Y., 1999. 3D crustal structure from local earthquake tomography around the Gulf of Arta (Ionian region, NW Greece). Tectonophysics 304, 201-218.

Kiratzi, A., Sokos, E., Ganas, A., Tselentis, A., Benetatos, C., Roumelioti, Z., Serpetsidaki, A., Andriopoulos, G., Galanis, O., Petrou, P., 2008. The April 2007 earthquake swarm near Lake Trichonis and implications for active tectonics in western Greece, Tectonophysics 452, 51- 65.

Klein, F.W., 2002. User's guide to HYPOINVERSE-2000, a FORTRAN program to solve earthquake locations and magnitudes. U. S. Geological Survey Open File Report 02- 606, Version 1.0.

Lee, W. H. K., R. E. Bennett, and K. L. Meagher, 1972. A method of estimating magnitude of local earthquakes from signal duration, Open File Report, U. S. Geological Survey, 28 pp.

Lee, W.H.K. and J.C. Lahr, 1975. HYPO 71: A computer program for determining hypocenter, magnitude, and first motion pattern of local earthquakes. USGS Open file report, p75-311.

Lee, W. H. K. and C. M. Valdes, 1985. HYP071PC: A personal computer version of the HYPO71 earthquake location program, U. S. Geological Survey Open File Report 85-749, 43 pp.

Lomax, A.J., 1991. User Manual for SeisGram. In Digital Seismogram Analysis and Waveform Inversion, IASPEI Soft ware Library Volume 3, W.H.K. Lee, ed., Seismological Society of America.

Melis, N.S., Brooks,M., Pearce, R.G., 1989.Amicroearthquake study in the Gulf of Patras region, west- 
ern Greece, and its seismotectonic interpretation. Geophys. J. Int. 98, 515-524.

Paige C. C. and. Saunders M. A, 1982. LSQR: An algorithm for sparse linear equations and sparse least squares, TOMS 8(1), 43-71.

Papazachos, C.B., Kiratzi, A.A., 1996. A detailed study of the active crustal deformation in the Aegean and surrounding area. Tectonophysics 253, 129-153.

Pikoulis V.E., Psarakis E.Z., Sokos E.N. 2006. A New Two Step Correlation Based Technique for the Classification of Seismic Events. Poster Section of First European Conference on Earthquake Engineering and Seismology, Geneva, Sept.

Pikoulis V.E., Psarakis E.Z. and Sokos E.N. A Novel Seismic Data Processing Technique for the Event Relocation Problem. Bulletin of the Seismological Society of America (to be submitted).

Psarakis E. and Evangelidis G. 2005. An Enhanced Correlation-Based Method for Stereo Correspondence with Sub-Pixel Accuracy. Proc. of Inter. Conference on Computer Vision, ICCV05, pp.907-912, Beijing.

Roumelioti, Z., A. Kiratzi and N. Melis, 2003. Relocation of the July 26, 2001 Skyros island (Greece) earthquake sequence using the double-difference technique, Physics of the Earth and Planetary Interior, Vol. 138, 231 - 239.

Waldhauser, F., , 2001. HypoDD: A computer program to compute double-difference hypocenter locations, U.S. Geol. Surv. open-file report, 01-113, Menlo Park, California.

Waldhauser, F., Ellsworth, W.L., 2000. A double-difference earthquake location algorithm: method and application to the Northern Hayward fault, California. Bull. Seismol. Soc. Am. 90, 1353-1368.

Wells, D.L., Coppersmith, K.J., 1994. New empirical relationships among magnitude, rupture length, rupture width, rupture area, and surface displacement. Bull. Seismol. Soc. Am. 84, 974-1002. 